\title{
CONSTRUÇÃO DO SUJEITO E COMPREENSÃO DO MUNDO EM EJA A PARTIR DE EXPERIÊNCIA E HISTÓRIA EM HANS-GEORGE GADAMER
}

\author{
Cláudio Roberto Brocanelli \\ Universidade Estadual Paulista - UNESP. Faculdade de Filosofia e Ciências, Marília - SP. E-mail: \\ claudiobrocanelli@gmail.com
}

\section{RESUMO}

Este texto é resultado parcial do estudo teórico-bibliográfico em busca do entendimento sobre o tema da experiência, durante meu doutoramento nos anos de 2006 a 2010. Nele abordo o pensamento de Gadamer acerca da hermenêutica como possibilidade de compreensão maior sobre a realidade em que vivemos e a apropriação desta mesma realidade como seus sujeitos. A hermenêutica é um campo de estudos que se ocupa com a compreensão de palavras ou mensagens de textos mais antigos; porém, Gadamer traz o seu sentido para além da compreensão da palavra, inserindo-a como condição para o entendimento da realidade em que cada pessoa vive. Assim, ofereço aqui a oportunidade de pensar a construção do sujeito e a compreensão do mundo a partir de cada experiência, que é sempre individual. Para pensar a EJA, esta ideia dá luz no sentido de uma busca de desvelamento da verdade estabelecida, que está aí, mas não é absoluta. Neste momento desejo que a discussão nos faça pensar em nossa condição de vida atual. É comum as pessoas se submeterem e se resignarem diante de condições de vida indigna afirmando que 'é assim mesmo' e não há como mudar. No entanto, nossa intenção, em especial com os estudantes de EJA, é desvelar esta situação obscura que esconde vidas sofridas que, apesar disso, podem ser modificadas e participantes de condições igualitárias, organizando formas de vidas menos injustas. É possível pensar e almejar outras formas de vida que não seja somente a da resignação, acomodação e dominação.

Palavras-chave: Educação. Experiência. Hermenêutica. EJA.

\section{CONSTRUCTION OF SUBJECT AND UNDERSTANDING OF THE WORLD IN EJA FROM EXPERIENCE AND HISTORY IN HANS-GEORGE GADAMER}

\begin{abstract}
This text is partly a result of theoretical and bibliographical study in search of understanding on the subject of experience, during my PhD in the years 2006-2010. Him aboard Gadamer's thought about the possibility of hermeneutics as a greater understanding of the reality in which we live and ownership of the same reality as their subject. Hermeneutics is a field of study that deals with understanding words or messages older texts; however, Gadamer brings his sense beyond the comprehension of the word, inserting it as a condition for understanding the reality in which each person lives. So I offer here a chance to think the construction of the subject and understanding of the world from every experience, which is always individual. To think EJA, this idea gives light towards a search of unveiling established truth, which is there, but it is not absolute. At this time I wish that the discussion makes us think of our current living condition. It is common for people to submit and resign before conditions unworthy life stating that 'it anyway' and there's no change. However, our intention, particularly with students EJA, is unveiling this obscure situation hiding lives of suffering that nevertheless can be modified and participants of equal conditions, organizing forms of unfair least lives. You can think and aspire to other forms of life that is not only the
\end{abstract}


resignation, accommodation and domination.

Key words: Education. Experience. Hermeneutics. EJA.

"Aos esfarrapados do mundo $e$ aos que neles se descobrem e, assim descobrindo-se, com eles sofrem, mas, sobretudo, com eles lutam". (Freire). 
É sempre conveniente iniciar com as 'primeiras palavras' de Paulo Freire...

Com este texto desejo trazer uma reflexão acerca da realidade que ainda assola a vida de muitos brasileiros, mantendo-os à margem da sociedade e distantes do acesso aos bens de consumo e culturais. No Brasil, apesar de haver a Constituição de 1988 e a Lei de Diretrizes e Bases da Educação Nacional de 1996 que garantem que todos têm direito de acesso à escola e à educação de qualidade, existe um grande número de pessoas que se mantém ou são mantidas nesta margem, impedidas e impotentes diante de condições de vida indignas.

Minha experiência atual com EJA resgata ideias de Hans-George Gadamer a fim de auxiliar na reflexão acerca desta realidade muito presente e próxima de nosso contexto social que, no entanto, nem sempre é visto e compreendido pela maioria dos que estão à frente de instituições ou liderando algum tipo de movimento político e social. Há políticas públicas e dedicação de muitas pessoas a fim de que tal realidade seja transformada. Porém, ainda assim, não há claramente a compreensão daquele que está marginalizado. Para grande número de pessoas, assim como elas nascem, devem se manter socialmente. Isto, sabemos, não é verdade. Então, é necessário que esta reflexão não permaneça nos meios acadêmicos somente, mas que ela invada os ambientes em que estas pessoas frequentam a fim de que efetivamente a sua realidade seja estampada e reclame mudanças, denunciando as condições de vida indigna e anunciando outras formas possíveis.

Pensar a vida como experiência vai além de políticas públicas, auxílios, escolarização, etc. É fundamental que as reflexões ofereçam condições de inverter a ordem social estabelecida por outrem, possibilitando que cada pessoa, sendo sujeitos e protagonistas de suas vidas, busquem cotidianamente e processualmente as mudanças necessárias para uma forma de vida digna, não resignada e submetida a decisões alheias.

A experiência humana e a sua compreensão no mundo e na história são os problemas que instigaram as reflexões de Gadamer a partir do estudo da fenomenologia hermenêutica de Martin Heidegger. Se este buscava o desenvolvimento de uma pré-estrutura da compreensão, Gadamer entra nessa problemática para entender como a hermenêutica apresenta a historicidade da compreensão. Há uma exigência fundamental que deve ser pensada sempre, quando estamos exercendo a compreensão de algo. Como em um texto, de acordo com a explicação de Heidegger, "A compreensão somente alcança sua verdadeira possibilidade, quando as opiniões prévias, com as quais ela inicia, não são arbitrárias." (GADAMER, 1997, p. 403). Não se pode dirigir ao texto ou a uma realidade diretamente, seguindo opiniões alheias e prévias; caso isso ocorra, que tais opiniões sejam examinadas quanto à sua legitimação; quando somos levados pelas opiniões e regras 
externas, somos impossibilitados do conhecimento "verdadeiro" e legítimo de uma tal realidade e, consequentemente, expropriados da experiência. Gadamer busca, nesse sentido, descobrir e demonstrar uma saída possível de conscientização das diferenças entre o uso da linguagem e opiniões costumeiras para a verdadeira compreensão da realidade (ou de um texto).

De modo geral, entendo que é a 'experiência do choque' com um texto que nos faz parar, por estranhamento, para perceber algo diferente do uso costumeiro de nossa língua e pensamento. Daí surge o desejo da compreensão da realidade, pois de outro modo, se corre o risco de manter a compreensão imediata e incorreta a partir de um hábito linguístico adotado pelas influências externas. "Quando se ouve alguém ou quando se empreende uma leitura, não é necessário que se esqueçam todas as opiniões prévias sobre seu conteúdo e todas as opiniões próprias. O que se exige é simplesmente a abertura à opinião do outro ou à do texto." (GADAMER, 1997, p. 404). E é esta abertura que permitirá uma relação com o outro e com outros pensamentos desconhecidos até então, permitindo a compreensão.

Suponho uma abertura, um cuidado e um olhar atento a tudo o que se nos apresenta e nos passa em nossa vida. Como realizamos nossas vivências dentro de uma história, é comum a tentativa de entender cada fenômeno histórico a partir de uma distância histórica que determina nossa situação hermenêutica como um todo, e nos encontramos sempre sob os efeitos dessa história 'efeitual'. "Ela determina de antemão o que se mostra a nós de questionável e como objeto de investigação, e nós esquecemos logo a metade do que realmente é." (GADAMER, 1997, p. 449). Sempre que tomamos os fenômenos imediatos como verdade, esquecemos ou não alcançamos toda a verdade desses fenômenos, presos a uma objetividade dos fatos.

Uma problemática impõe-se ao pensamento de Gadamer quando se pretende aplicar praticamente a hermenêutica como método de toda compreensão, o que forçaria a tomar uma reflexão universal para o entendimento de situações concretas e particulares. Para não cometer a destruição da hermenêutica e a compreensão da vida e suas relações, ele recorre à ética aristotélica; uma preocupação no pensamento de Aristóteles que trata do papel que a razão desempenha na atuação ética (Cf. GADAMER, 1997, p. 465). Aristóteles apresenta a preocupação com o ser humano no sentido de que não se restringe a um mundo físico e determinado pela ação de capacidades e forças, mas que "vivencia" seus limites humanos e formas de um comportamento ético, tendo uma maneira de se comportar no mundo. "No terreno do problema ético não se pode falar em exatidão, de nível máximo, como a que fornece o matemático." (GADAMER, 1997, p. 467).

$\mathrm{Na}$ condição ética que vive o homem, em grande medida, o que acontece o afeta, 
imediatamente, exigindo também uma atitude. A vida não é tekne; esta é uma habilidade, como o saber do artesão que produz objetos determinados. A questão é: como acontece na vida humana, que não é acabada enquanto há a vida, envolta em momentos e experiências que lhe exigem uma resposta? Pois o homem não pode produzir-se a si mesmo da mesma forma com que produz e reproduz as coisas úteis para a sua vida.

Por conseguinte, o saber que tenha de si mesmo, em seu ser ético, será diferente e se destacará claramente do saber que guia um determinado produzir. Aristóteles formula essa diferença de um modo audaz e único, chamando a esse saber de saber-se, um saber para si. Com isso, o saber-se da consciência ética se destaca do saber teórico de um modo que para nós se torna particularmente elucidativo. (GADAMER, 1997, p. 471).

Desse modo, a tarefa mais importante da vida humana, que é ao mesmo tempo um desafio, é a decisão ética na busca de encontrar respostas às situações concretas. Em momentos como esse, o homem está determinado e tende a dar uma resposta que para ele será a mais correta e adequada a cada situação. É fundamental ao homem, para a sua vida em constante experiência e ciência de si, que ele perceba-se no mundo; é necessário saber-se no mundo, entender-se e compreender-se. Em resumo: enxergar o que acontece, seja de forma ativa ou passiva, seja a partir de suas intenções ou a partir das interferências externas.

Aquilo que faz parte do universo técnico (tekne) pode ser aprendido e também esquecido em algum momento. Porém,

o saber ético não pode ser aprendido e nem esquecido. Não nos confrontamos com ele de maneira que dele possamos nos apropriar ou não nos apropriar, da mesma forma que se pode eleger um saber objetivo, uma tekne. Pelo contrário, encontramo-nos sempre na situação de quem tem de atuar e, por conseguinte, temos de já sempre possuir e aplicar o saber ético. (GADAMER, 1997, p. 472).

Não há uma imagem a ser reproduzida como a tem um artesão ou um pintor de paisagens; nestes, aquilo que eles querem realizar já está determinado de antemão (um desenho do objeto e as regras para sua execução), independentemente de suas tendências internas. A atitude ética, por sua vez, depende de uma disposição humana diante de situações que se lhe aparecem em momentos que são, muitas vezes, inesperados, exigindo uma resposta no momento atual da situação concreta ${ }^{1}$.

\footnotetext{
${ }^{1}$ Volta-se assim contra o convencionalismo extremado ou o positivismo jurídico, e distingue claramente entre direito natural e direito positivo. É verdade que, em geral, temos entendido Aristóteles nesse sentido, mas com isso se passa por alto a verdadeira profundidade de sua concepção. Aristóteles conhece efetivamente a ideia de um direito inalterável, mas a limita expressamente aos deuses e declara que entre os homens não só é alterável o direito positivo, mas também o natural. Essa alterabilidade é, segundo Aristóteles, perfeitamente compatível com o caráter "natural" desse direito. O sentido dessa afirmação me parece ser o seguinte: existem efetivamente leis jurídicas que são, inteiramente, coisa da conveniência (por exemplo, as normas de trânsito, como a de conduzir pela direita); mas existem também aquelas que não permitem uma convenção humana qualquer, porque a "natureza das coisas" tende a se impor constantemente. A essa classe de leis pode se chamar justificadamente de "direito 
Em determinadas situações da vida humana, ou na maioria delas, não é possível empregar uma forma dogmática, uma fórmula que lhe dê respostas exatas às suas experiências. Isso pode valer para valores correspondentes a uma época, recebendo mudanças constantes, bem como para muitas experiências particulares, exigindo sua resposta. Mesmo para o professor de ética, suas explicações indicam imagens diretrizes que valem como esquemas, mas isso não corresponde a um ensino da ética; "Elas se concretizam sempre só na situação particular do que atua." (GADAMER, 1997, p. 476).

Desse modo, é preciso entender a estrutura da experiência, a qual permite a compreensão e a consciência histórica. Para Gadamer, o conceito de experiência é um dos que menos possuímos, apesar de vivermos e nos formarmos sempre por meio dela. Um problema que ratifica esse paradoxo é a orientação científica que regula a humanidade e suas vivências, desapercebendo-se da historicidade interna da experiência.

O escopo da ciência é objetivar a experiência até que fique livre de qualquer momento histórico. No experimento natural-científico consegue-se isso através do modo de seu aparato metodológico. Algo parecido realiza também o método histórico-crítico nas ciências do espírito. Num e noutro caso a objetividade ficaria garantida pelo fato de que as experiências que jazem ali poderiam ser repetidas por qualquer pessoa. Tal como na ciência da natureza os experimentos tem de ser possíveis de comprovação posterior, também nas ciências do espírito o procedimento completo tem que ser passível de controle. Nesse sentido, na ciência não pode restar lugar para a historicidade da experiência. (GADAMER, 1997, p. 513).

A ciência moderna continua com seu método de análise e conhecimento por meio de testes e afirmações que devem ser confirmadas, aceitas e aplicadas novamente, não restando dúvidas; toda experiência nesse âmbito só tem validade se confirmada e reproduzida. Todo o conhecimento surge, ou pode vir a ser, a partir de um estudo que se processa gradativamente, de um problema particular para um geral que garantirá uma aplicação a todos os fatos; nisso se alcançará uma experiência ordenada e capaz de evitar precipitações, uma experiência científica estruturada. Organiza-se logicamente o pensamento e os problemas encontrados para obter soluções, da forma mais acertada possível.

Gadamer mostra o sentido de não nos limitarmos ao aspecto teleológico que tem dominado as reflexões filosóficas sobre o problema da experiência até o momento. Ainda que tais reflexões compreendam corretamente um momento verdadeiro da estrutura da experiência, esta tem sido tratada como válida enquanto não contradita por uma nova experiência, reforçando a 
importância de uma validade que seja transmitida a todos como uma essência geral da experiência (Cf. GADAMER, 1997, p. 517). Sua validade, seja na organização científica no sentido moderno ou nas experiências de vida cotidiana, desse modo, faz parte de uma estrutura pensada e organizada anteriormente, caracterizando a cientificidade e garantindo a transparência das experiências.

O que pretendo reforçar, a partir dos estudos já apresentados aqui e dessa reflexão de Gadamer sobre a hermenêutica, é "que a experiência tem lugar como um acontecer de que ninguém é dono, que não está determinada pelo peso próprio de uma ou outra observação, mas que nela tudo se ordena de uma maneira impenetrável." (GADAMER, 1997, p. 520). Tem-se, assim, um momento da experiência que é inesperado e outro que, por se tratar de algo que já foi experienciado, pode ser previsto; mas somente um novo fato inesperado, um acontecimento, pode proporcionar uma nova experiência. Assim, o maior sentido de toda experiência está no seu processo, e não na perspectiva de um resultado.

Partindo dessas reflexões filosóficas sobre a experiência, Gadamer nos apresenta a existência de alguns contrapontos, especialmente quando trata do pensamento de Hegel no que se refere à experiência e um resultado, a ciência, sendo esta a consumação da experiência e a certeza de si mesmo no saber, ou seja, um saber-se. Para pensar o problema da experiência, Gadamer fixa sua reflexão no momento anterior da consumação de toda experiência, em seu processo e na abertura a novas experiências.

Nesse sentido a pessoa a que chamamos experimentada não é somente alguém que se fez o que é através das experiências, mas também alguém que está aberto a experiências. A consumação de sua experiência, o ser pleno daquele a quem chamamos experimentado, não consiste em ser alguém que já conhece tudo, e que de tudo sabe mais que ninguém. Pelo contrário, o homem experimentado é sempre o mais radicalmente não dogmático, que, precisamente por ter feito tantas experiências e aprendido graças a tanta experiência, está particularmente capacitado para voltar a fazer experiências e delas aprender. A dialética da experiência tem sua própria consumação não num saber concludente, mas nessa abertura à experiência que é posta em funcionamento pela própria experiência. (GADAMER, 1997, p. 525).

Pensar desse modo a experiência humana, o pensamento humano como nos propõe Gadamer, requer aceitar os limites humanos de conhecimento para, de algum modo, chegar ao conhecimento dos objetos, não sendo este, no entanto, o fim mais importante. Isso seria adiantar toda reflexão e saber por meio da experiência superada, já acontecida, e não considerar todo o processo e suas limitações. Portanto, não importa o rigor da experiência para ensinar tal ou qual coisa, mas o todo de seu processo que faz parte da essência histórica do homem e a ninguém 
pode ser poupado.

É por isso que as experiências, fazendo parte da vida e da história humana, não podem ser rigidamente dirigidas, como nas preocupações dos pais com os filhos, os quais buscam sempre dirigir ou poupar sua vida de experiências. E aqui não podemos afirmar tampouco que devemos permitir certas experiências, pois isso também não é possível; permitir também seria uma forma de direção predeterminada.

Gadamer reconhece em Ésquilo ${ }^{2}$ o melhor entendimento que expressa a historicidade interna da experiência. Aprender pelo sofrer. Porém, "o que o homem deve aprender pelo sofrer não é isto ou aquilo, mas a percepção dos limites de ser homem." (GADAMER, 1997, p. 527). Então, experiência é a experiência da finitude humana. Aquele que tem consciência desta limitação pode ser considerado experimentado, pois sabe que não é senhor do tempo nem do futuro. "O homem experimentado, propriamente, conhece os limites de toda previsão e a insegurança de todo plano. Nele consuma-se o valor de verdade da experiência. [...] Nela chega ao limite absoluto todo dogmatismo nascido da volátil possessão pelo desejo do ânimo humano." (GADAMER, 1997, p. 527). É pelo reconhecimento consciente do homem sobre sua finitude que se torna possível a verdadeira experiência. Não é possível, como já indicamos, dirigir absolutamente o curso da vida humana, pensando ser possível voltar atrás, fazer tudo ou trazer de volta o que já foi, mas somente perceber os limites dentro dos quais há possibilidades e uma historicidade humana.

Assim, pensar com Gadamer o sentido humano na atualidade, em especial, considerar as vidas ameaçadas, desvalidas, marginalizadas e algumas esfarrapadas, é pensar em possibilidades de reconhecimento das limitações e supor as potencialidades para tal superação. O estudante de EJA fez uma história, teve uma vida, a sua história; no entanto, enquanto há vida é possível alcançar mudança e dignificar o presente por meio da luta por participação em um mundo que seja, ao menos, um pouco mais justo. Se não é possível alcançar o utópico, que seja feita a revisão constante da política e da sociedade a fim de experimentar de alguma forma a utopia e alimentar a vida com 'possíveis' mais próximos da dignidade humana. Esta dignidade não é de um, de poucos ou de um grupo, mas deve ser de todos. Que os governantes e líderes pensem nisso; façam memória de que eles mesmos são seres humanos também, não se esquecendo dos mais fracos da 'civilização'.

\footnotetext{
2 Ésquilo, autor trágico de Elêusis, Grécia Antiga, nascido no ano 525 a.C., acreditava que o autor era, antes de tudo um educador. Dava importância ao "sofrimento em cena", uma experiência durante a apresentação teatral que afetasse o expectador, fazendo-o despertar para os sentimentos sofridos na cena, causando alívio ou purgação desses sentimentos e uma purificação das paixões. (acesso aos 04/12/2009, Ésquilo:http://www.mundocultural.com.br/index.asp?url=http://www.mundocultural.com.br/literatura1/grega/esquilo.htm).
} 


\section{REFERÊNCIAS}

FREIRE, P. Pedagogia do Oprimido. 17ạ. Edição. Rio de Janeiro: Paz e Terra. 1987.

. Educação como prática da liberdade. 30ạ. Edição. Rio de Janeiro: Paz e Terra, 2007.

GADAMER, H.G. Verdade e método: traços fundamentais de uma hermenêutica filosófica. Tradução de Flávio Paulo Meurer. Petrópolis, RJ: Vozes, 1997.

HADDAD, S. A ação de governos locais na educação de jovens e adultos. Revista Brasileira de Educação, Volume 12, número 35. Maio/Agosto de 2007. 